\title{
Experiments and thermodynamics: their influence on the development of metamorphic petrology \\ BERNARD J WOOD
}

Earth Sciences, University of Oxford

Presenting Author: bernie.wood@earth.ox.ac.uk

Metamorphic petrology grew, flourished and in some views died from a mixture of careful petrography, experimental petrology and thermodynamics. Here I will consider the impacts of experiments and thermodynamics on the modern quantitative approach to metamorphism. George Barrow in his (1893) paper on metamorphism in the Scottish highlands correctly deduced that the progression from Kyanite to Sillimanite zones was a response to increasing temperature. But this correct deduction was based on incorrect experimental data. Nevertheless, experiments had made their mark and thermodynamics was soon employed in Goldschmidt's 1912 demonstration of the conditions of the breakdown of calcite + quartz during contact metamorphism. Eskola's (1920) concept of metamorphic facies led to a more systematic approach. Experiments started to be applied seriously starting in the late 1940's using cold-seal type hydrothermal vessels. At the beginning little attention was paid to the starting materials and experimentalists used a wide variety including co-precipitated (highly unstable) gels, glasses, oxide mixes and natural minerals. These led to some rather strange results, not helped by petrologists pointing out that many phase diagrams (e.g the $\mathrm{Al}_{2} \mathrm{SiO}_{5}$ diagram) made no geological sense. The principal issues revolved around the value of synthesis experiments as a means of determining equilibrium diagrams. JB Thompson (1955) showed how thermodynamics could be applied to understand how reactions should plot on a P-T or chemical potential diagram. Fyfe, Turner and Verhoogen,(1958) produced their classic memoir on metamorphic reactions and metamorphic facies, which, followed by Fyfe's (1960) paper set the scene for the future of experimental studies : (1)Highly unstable starting materials to be avoided (2)Demonstration of reversal as proof of equilibrium (3)Solubility of phases on both sides of a reaction as a means to better constrain equilibrium. (4) Integration of phase equilibrium data with calorimetry. The solubility idea led to use of a single crystal of one of reactants or products as a means to determine reaction direction precisely. Thus we arrived in 1978 (Helgeson et al) at an internally-consistent thermodynamic database for many of the rock-forming minerals, the precursor of more extensive treatments such as Holland and Powell's THERMOCALC. 